\title{
The history of neurosurgery and its relation to the development and refinement of the frontotemporal craniotomy
}

\author{
D. Ryan Ormond, M.D., ${ }^{1}$ and Costas G. Hadjipanayis, M.D., Ph.D. ${ }^{2}$ \\ ${ }^{1}$ Department of Neurosurgery, University of Bonn, Germany; and ${ }^{2}$ Department of Neurosurgery, Emory \\ University School of Medicine, Atlanta, Georgia
}

\begin{abstract}
The history of neurosurgery is filled with descriptions of brave surgeons performing surgery against great odds in an attempt to improve outcomes in their patients. In the distant past, most neurosurgical procedures were limited to trephination, and this was sometimes performed for unclear reasons. Beginning in the Renaissance and accelerating through the middle and late 19th century, a greater understanding of cerebral localization, antisepsis, anesthesia, and hemostasis led to an era of great expansion in neurosurgical approaches and techniques. During this process, frontotemporal approaches were also developed and refined over time. Progress often depended on the technical advances of scientists coupled with the innovative ideas and courage of pioneering surgeons. A better understanding of this history provides insight into where we originated as a specialty and in what directions we may go in the future. This review considers the historical events enabling the development of neurosurgery as a specialty, and how this relates to the development of frontotemporal approaches.
\end{abstract}

(http://thejns.org/doi/abs/10.3171/2014.2.FOCUS13548)

KEY WORDS • frontotemporal craniotomy $・$ history $・$ pterional •
keyhole approach

$\mathrm{T}$ HE history of neurosurgery is filled with courageous individuals who worked against great odds in an attempt to improve the lives of their patients. For centuries, the realm of neurosurgery was considered an arena mostly of observation and "primum non nocere," as surgical outcomes were often worse than disease progression. The Hippocratic School was the first to codify treatment for head injury in De capitis vulneribus, with skull fractures being classified by type and the severity of injury determining the need for trephination (the worse the injury, the less the need for trephination) ${ }^{43}$ Furthermore, this work did not provide any clues that the neurological condition of the patient made any difference in the surgical decision-making process. ${ }^{35}$

The Renaissance in Europe saw a dramatic improvement in the understanding of anatomy and the development of surgical techniques. Jacopo Berengario da Carpi (1460-1530) was an Italian physician, surgeon, and anatomist, who was the first to publish an anatomical text supplemented with illustrations. ${ }^{76} \mathrm{He}$ also published a monograph dedicated to head injury, De fractura Cranii, the second after Hippocrates' work. ${ }^{5-8}$ Carpi was motivated to write this text shortly after treating a serious head injury in Lorenzo dé Medici. He had a dream in which a capped man with golden-winged sandals encouraged him to write a treatise on head injuries. ${ }^{35}$ The next few centu- ries witnessed great advances in anatomical knowledge, but until further developments in the areas of cerebral localization, anesthesia, hemostasis, and antisepsis occurred, neurosurgery remained in its infancy.

\section{Anesthesia, Antisepsis, and Hemostasis}

Major advances in three areas of science and medicine-anesthesia, antisepsis, and hemostasis-dramatically improved the safety and efficacy of surgery. One of the evolutionary changes in Western medicine occurred under the hands of Ambrose Paré (1510-1590) in the mid16th century. A Huguenot and military surgeon, Paré rejected the long-held practice of boiling oil and hot cautery for hemostasis and instead found that ligatures offered superior hemostasis and wound healing..$^{75} \mathrm{He}$ popularized his findings by writing in French instead of Latin and was surgeon to the European royal courts. ${ }^{16,35}$ Cautery returned later as electrocautery devices were improved and popularized by William T. Bovie (1881-1958) and Harvey Cushing (1869-1939). ${ }^{66}$ Cushing used Bovie's device for the first time on October 1, 1926, to successfully remove a skull myeloma from the head of a 64-year-old patient, which he had failed to remove previously because of its vascularity. ${ }^{66}$ Improved methods of hemostasis coincided with the development of safe blood transfusion. William 


\section{R. Ormond and C. G. Hadjipanayis}

Harvey (1578-1657) had discovered the circulation of blood in $1628,{ }^{39}$ and the first successful animal transfusion between two dogs had been performed by Richard Lower (1631-1691) in 1665. ${ }^{61}$ A few years later Lower also performed the first blood transfusion from a sheep to a human (xenotransfusion) for the treatment of mental illness in a clergyman. ${ }^{61}$ Unfortunately, difficulties with transfusion reactions, clotting, and incompatibility were not resolved until blood groups were discovered by Karl Landsteiner (1868-1943) much later, in $1900{ }^{86}$ With the development of better hemostasis and successful blood transfusions, the stage was set for more complex surgery. However, surgeons needed to overcome the other major limitations to successful surgery: pain and infection.

While wine and opium have been used for their sedative and analgesic effects for millennia, a dramatic change in the understanding and use of anesthetic agents in the 18 th and 19th centuries enabled the surgeon to operate in patients while they remained pain free for extended periods of time. ${ }^{7,50,79,82}$ Generations of physicians in the East and the West used various herbal concoctions with some success. Ultimately, the consistent use of anesthetic agents in surgery occurred following the discovery of nitrous oxide, diethyl ether, and other agents during the 19th century. The Pneumatic Institution for Inhalation Gas Therapy was founded in 1798 at Dowry Square in Clifton, Bristol, England. Here, Humphry Davy (1778-1829) discovered nitrous oxide and coined the term "laughing gas." ${ }^{20}$ Davy documented its analgesic effects and potential benefits in relieving pain during surgery. ${ }^{20}$ By the 1830 s, "ether frolics" were held in the northeastern United States, where participants inhaled either diethyl ether or nitrous oxide to demonstrate their mind-altering properties as a form of entertainment. ${ }^{22}$ Four men participating in these events later became instrumental in the use of these agents in surgery: William Edward Clark (1819-1898), Crawford W. Long (1815-1878), Horace Wells (1815-1848), and William T. G. Morton (1819-1868). ${ }^{22}$ As a medical student at Berkshire Medical College in 1842, Clark gave diethyl ether to a Miss Hobbie while Elijah Pope performed a dental extraction, completing the first surgical procedure under general anesthesia in the modern era. ${ }^{62}$ That same year in the state of Georgia, Crawford Long removed a tumor from the neck of a man who was under ether anesthesia. ${ }^{60}$ Long went on to utilize ether anesthesia as a general anesthetic for limb amputations and parturition. ${ }^{60}$ However, the widespread use of ether anesthesia did not begin until Wells and Morton successfully demonstrated its use publicly at Massachusetts General Hospital in $1846 . .^{70}$ Further developments in anesthetic agents continued in Europe during this same time period. One important example involved James Young Simpson (1811-1870), who frequently experimented with various agents in his dining room to see if they had anesthetic effects. On November 4, 1847, Simpson sat with two of his friends as they decided to try chloroform. After inhaling the chemical, they felt a general mood of "cheer and humour" and then collapsed, to regain consciousness only the next morning. ${ }^{85}$ Simpson knew he had found something he could use as an anesthetic and began to use it in his obstetric practice in Edinburgh. ${ }^{85}$ These advances helped bring us into the modern surgical era, providing patients with the analgesia and anesthesia necessary to increase surgical time and complexity.

Beginning in the Middle Ages, various discoveries over several centuries eventually led to the rejection of old dogma and to the development of asepsis and antiseptic technique. Early on, antiseptic technique was not well understood. For example, Roger of Salerno (d. 1119), a 12th-century surgeon, promoted suppuration in open wounds. He believed it was helpful in the healing process. ${ }^{35,82}$ Air was later understood as the harbinger of the putrefactive process. As early as 1516, Magnatus described "miasms" that infected everything that was open and exposed to the air. ${ }^{16}$ Surgeons then made painstaking efforts to prevent air from getting into wounds. Antonie van Leeuwenhoek (1632-1723) later discovered microorganisms after developing his microscope and described his work in numerous letters to the Royal Society. ${ }^{16,28}$ Unfortunately, the connection between microorganisms and human disease did not truly develop until well into the 19th century. In the mid-19th century, surgical mortality due to postoperative sepsis remained nearly $50 \%$. While a number of individuals were involved in discoveries resulting in the reduction of postoperative sepsis, a few key individuals stand out as pivotal in the development of aseptic and antiseptic surgery. In the 1840s, Ignaz Semmelweis (1818-1865) was working in the maternity department of the Vienna Lying-in Hospital. After noting the difference in mortality from puerperal fever in doctor's wards versus midwives' wards, he hypothesized that this occurred because of a contagion transferred by the interns performing autopsies around the time that they performed deliveries. He required interns to wash their hands with a chlorinated lime solution and successfully decreased the mortality rate from over $10 \%$ to less than $1 \%{ }^{84,86,92}$ Unfortunately, his remarkable findings went against conventional medical "knowledge" of the day, and it would be decades before his findings would be widely accepted. ${ }^{40}$ In the $1860 \mathrm{~s}$, Louis Pasteur demonstrated that microorganisms cause spoilage, not "spontaneous generation" (the hypothesis that putrefaction occurred ex nihilo from bad air), and that microorganisms can travel through the air and be killed by heat. ${ }^{29}$ During this same time, Robert Koch (1843-1910) proved the germ theory of disease by describing Bacillus anthracis as the causative agent of anthrax. ${ }^{57}$ Building on this work and noting that carbolic acid-treated sewage reduced cattle infections, Joseph Lister (1827-1912) began spraying instruments, dressing wounds, and washing gloves and hands with dilute carbolic acid. He noticed dramatic reductions in postoperative sepsis. ${ }^{58,59}$ Antisepsis and sterilization proved among the most important advances to the value of surgery in the modern era.

Ultimately, improvements in anesthesia, antisepsis, and hemostasis brought surgery out of the dark ages of "prepare to meet thy God," into the modern era. ${ }^{73}$ Surgeries could now be performed over longer periods of time with the control of bleeding and without the devastating fears of sepsis from surgeries of the previous era. These advances ushered in a great renaissance in the development of new and more complicated surgical techniques to 
improve the lives of surgical patients. However, until the development of accurate cerebral localization, the brain was largely a "black box," which few dared to open.

\section{Cerebral Localization}

Our understanding of cerebral localization was hindered by long-held incorrect philosophies. Ancient philosophers and physicians believed that brain functions were carried out in the cerebral ventricles by "psychic pneuma," a light substance or spirit that enabled the animal to perform sensory, motor, and mental activities. ${ }^{64}$ This idea later developed into the three-cell theory, in which each ventricle (anterior, middle, and posterior) had a special function (for example, imagination, cognition, and memory, respectively) containing a unique power to perform that function. ${ }^{64}$ This theory began in the classical period in persons such as Galen of Pergamon (130-200), and then propagated through the Islamic Schools to the Latin West. Not until the Renaissance was this doctrine challenged to look for brain function in brain parenchyma itself. With the development of scientific inquiry, dissection, and experimentation, the cobwebs of the past began to be removed, and two competing theories of cerebral localization emerged.

Franz Joseph Gall (1758-1828) noticed that several peers in his youth could easily recite texts from memory, and he linked this talent to the shape of their orbit. He believed that psychic activities (for example, speech, perception, understanding, imagination, and so forth) localized to the cerebral convolutions. ${ }^{34,71}$ While containing many flaws, this theory was based on elaborate anatomical studies and drew attention to the fact that higher mental functions were processed in specific areas of the brain and were not just attributes of the soul. ${ }^{71}$ Gall's position created significant friction with the church, and he was ultimately expelled from Austria. However, Gall did gain many followers, and his observations were later developed by his pupil Johann G. Spurzheim (1778-1832) into phrenology - the theory that one could study the bulges on an individual's skull to determine where they had particular areas of brain hypertrophy corresponding to particular skills or personality traits. ${ }^{34,71}$

Jean P. Flourens (1794-1867) was a contemporary and a critic of phrenology. ${ }^{32}$ He performed progressive ablations and stimulations of the nervous system to define the function of each part, divided into peripheral nerves, spinal cord, brainstem, quadrigeminal protuberance, cerebellum, and cerebrum. ${ }^{31}$ Stimulation of the peripheral nerves, spinal cord, brainstem, and quadrigeminal protuberance produced motor responses, but cerebral stimulation did not. ${ }^{31,71} \mathrm{He}$ concluded that the cerebral hemispheres were responsible for feelings, understanding, and free will. He believed that these functions were located diffusely throughout the entire hemisphere. ${ }^{31}$ He termed this "cortical equipotentiality," believing that if part of the cerebrum were damaged, all of its functions would remain but would be less efficient. ${ }^{73}$ Both Fluorens' holistic theory and phrenology contained elements of truth along with significant errors. Flourens helped set in motion a period of scientific inquiry resulting in cerebral localization accurate enough to be relevant to surgical localization, a process led by individuals such as G. T. Fritsch (18371927), E. Hitzig (1839-1907), Paul Broca (1824-1880), Carl Wernicke (1848-1905), David Ferrier (1843-1928), and John Hughlings Jackson (1835-1911). ${ }^{10,11,30,33,35,89}$

In 1885, Alexander H. Bennett, a neurologist, successfully localized a tumor through physical examination and recommended removal to a surgeon; the tumor caused focal motor seizures and weakness. Sir Rickman Godlee (1849-1925) made an incision over the Rolandic area and successfully removed the tumor. ${ }^{4}$ This was the first time cerebral localization was successfully used to localize and remove a brain tumor. Three years later, Victor Horsley (1857-1916) first removed a spinal cord tumor in a patient whose tumor had been localized by William Gowers (1845-1915). ${ }^{36}$ Now equipped with improved means of anesthesia, antisepsis, hemostasis, and cerebral localization, surgeons could focus on developing increasingly complex techniques to improve the lives of neurosurgical patients.

\section{Classic Frontotemporal Craniotomy}

George Heuer (1882-1950) originally developed the frontotemporal craniotomy in 1914 as a means of getting better access to hypophysial tumors (Fig. 1). ${ }^{17,18,42}$ To better understand the benefits of his approach, it is worthwhile to discuss some predecessors who had some influence on the development of his techniques. Victor Horsley performed not only the first spinal cord tumor resection, but also the first pituitary adenoma operation in 1889. ${ }^{455}$ Horsley first performed a temporal craniotomy

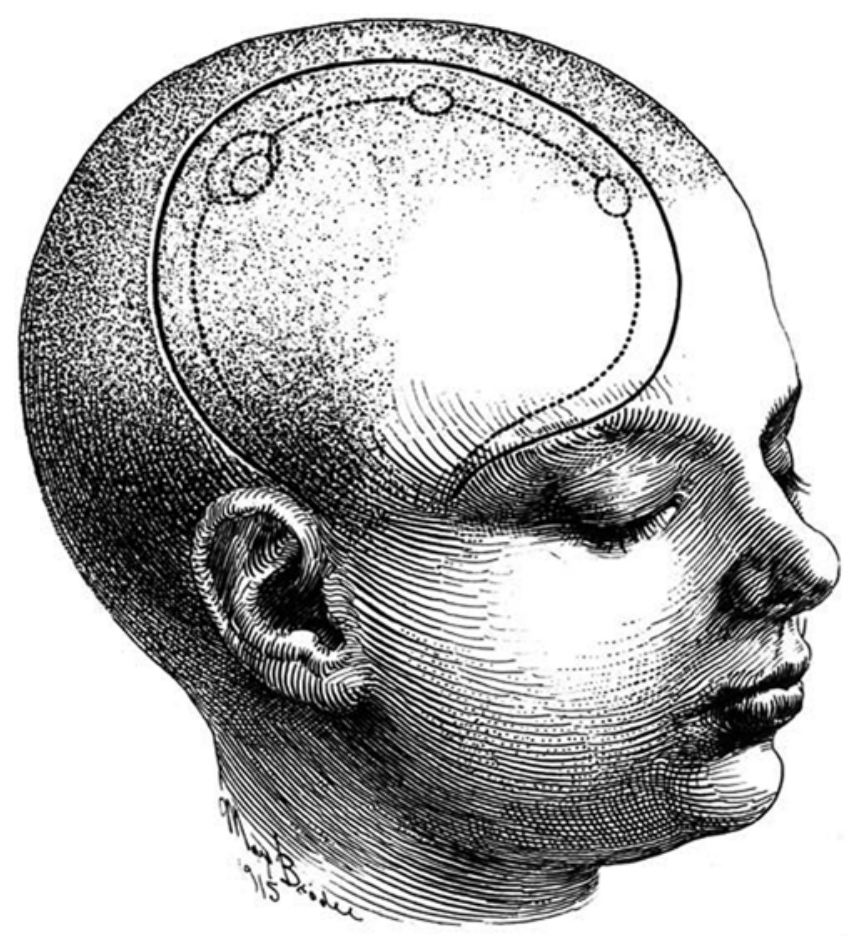

FIG. 1. Outline of the scalp and bone flap from Heuer's frontotemporal craniotomy. Reprinted from Heuer: Arch Surg 1:368-381, 1920. Copyright 1920 American Medical Association. All rights reserved. 


\section{R. Ormond and C. G. Hadjipanayis}

and then incised the dura mater and lifted the temporal lobe for exposure of the lateral aspect of the pituitary. He used a strong headlight and spatula to inspect the lateral region of the cerebellum and medulla, as well as a small rhinoscopy mirror placed in the sella to inspect the base of the brain. ${ }^{45}$ In 1893, Frank T. Paul (1851-1941) performed a decompressive temporal craniotomy on an acromegalic woman with increasing headaches; he had judged that the tumor could not be removed. The patient's headaches were relieved, although her sight was lost, and she died suddenly a few months later. ${ }^{14}$ In Berlin in 1900 , Fedor Victor Krause (1857-1937) successfully removed a bullet via a unilateral transfrontal approach in a suicidal patient. In 1905, he proposed and then performed a subfrontal extradural approach to the pituitary.51,52 In December 1903, Otto George Theobald Kiliani (1863-1928) used a bifrontal subfrontal intradural approach in an attempt to save the life of a patient with pituitary apoplexy with acute intratumoral and subdural hematoma, but he could not access the tumor because of cerebral edema and bleeding, and the patient died 8 hours later. ${ }^{48}$ In 1908 , but first reported in 1912, Louis Linn McArthur (1858-1934) performed a right frontal osteoplastic flap, resecting the supraorbital rim and part of the orbital roof to access the pituitary from an extradural approach, incising the dura $0.5 \mathrm{~cm}$ proximal to the chiasmatic sulcus. ${ }^{9,17,18,42,55}$ This gradual progression and experimentation by several surgeons during the years prior to 1914 helped to refine intracranial approaches and influenced Heuer in the development of his frontotemporal craniotomy.

Another surgeon key in influencing Heuer's techniques was Wilhelm Wagner (1848-1900) who developed the osteoplastic flap. ${ }^{90}$ Wagner considered trepanation ("removal of a piece of the intact bony calvarium") as a "mutilating surgery." ${ }^{\circ}$ He performed anatomical experiments for several years to devise a method to "resect optionally and temporarily a large piece of the calvarium so that it could be removed completely from its opening, but at the same time remain in connection with the soft parts that its healing would be assured." 90 Wagner described his osteoplastic flap in the following words.

By a cut in the form of the Greek $\Omega$ (omega), the soft parts of the pertinent sections of the skull are cut to the periosteum. When the flap retracts it is pressed firmly to the skull and along its edge a cut is made through the periosteum, running parallel to and inside of the first cut at the average distance of $0.5-1 \mathrm{~cm}$. Then the bone is chiseled completely through along the arched portion of this inner omega cut, whereas in the two legs of the omega only a groove is chiseled, from the external side inward. Two narrow chisels are inserted into this groove and, without injuring the soft parts lying above, the bony bridges are chiseled through subcutaneously.

The bony piece enclosed by the arched portion of the omega can now be lifted easily with narrow elevators and folded back parallel to the legs of the omega, together with the soft parts. Between these legs it and its overlying soft parts are connected with the remaining covering of the skull by means of a pedicle at least $3 \mathrm{~cm}$. wide.

This folded piece then is simply reinserted in its place. The flap of soft parts, which, in view of the difference in the cut made in the soft parts and in the bone, projects over the latter by about 1 $\mathrm{cm}$., then is sutured carefully, as are the legs of the omega after the drainage of the angles. The bony piece always fits well in its gap, especially if the small edges of the inner lamina which remain in the bony opening are allowed to remain as a shelf in order to prevent the sinking in of the resected part. ${ }^{90}$

Wagner's osteoplastic flap was subsequently widely adopted by many neurosurgeons around the world and influenced Heuer in his surgical development. Heuer later incorporated the osteoplastic flap into his frontotemporal approach. ${ }^{42}$

The beauty of Heuer's approach was that it involved a shorter, more oblique approach to the chiasmal region along the sphenoid ridge, allowing wider exposure, giving better access and visualization to the chiasmal region (Fig. 2). ${ }^{9}$ Heuer's approach was initially described by Walter Dandy (1886-1946) to speed its publication (at the insistence of William Halsted [1852-1922]), because Heuer was in France during World War I. ${ }^{1718}$ After Heuer's return from World War I, however, he reported the procedure himself in a series of patients with chiasmal lesions. ${ }^{42}$ In this work, we read his firsthand account of the operation, its benefits and limitations as he saw them, and his first patient experience with the new approach. He presented his intracranial approach as an option alongside transsphenoidal operations to chiasmal lesions. He saw the transsphenoidal operation as ideal for "early cases which present sellar headaches and evidences of secretory derangement." ${ }^{40}$ His intracranial approach was

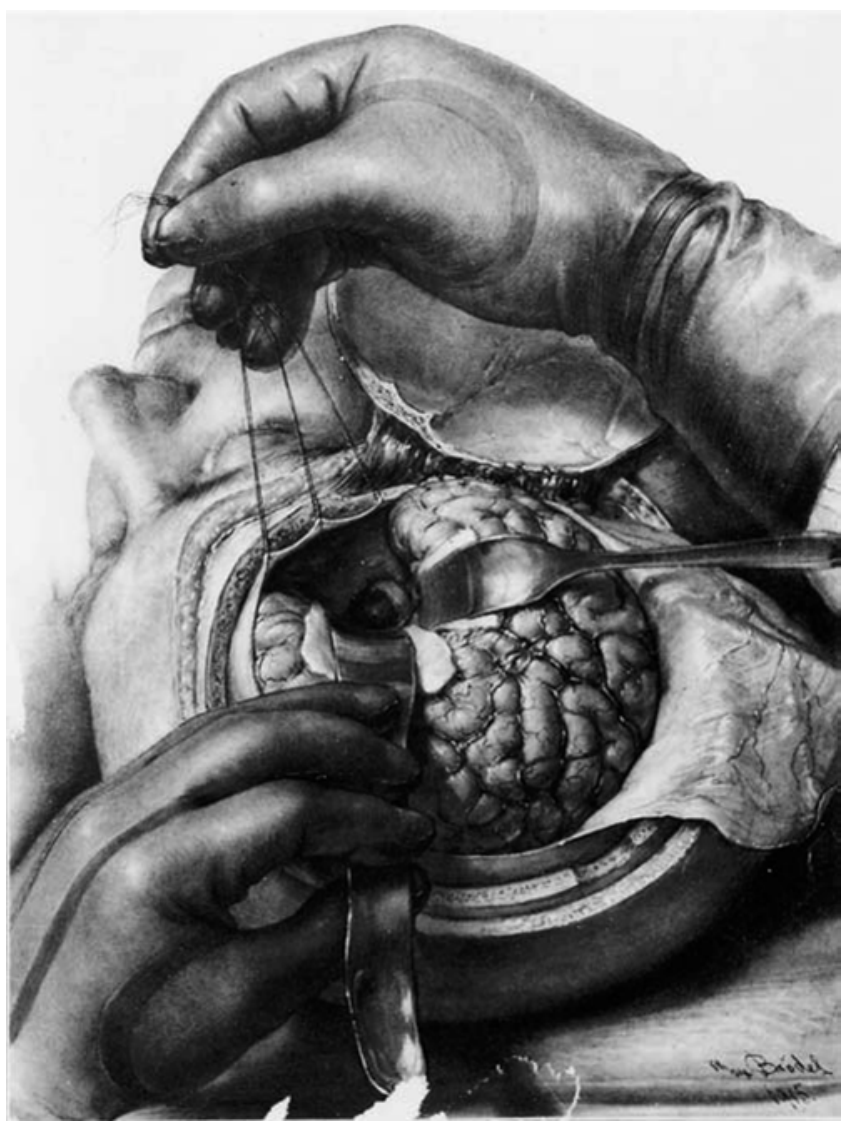

FIG. 2. Drawing of the intraoperative exposure with the frontal lobe retracted. Reprinted from Heuer: Arch Surg 1:368-381, 1920. Copyright 1920 American Medical Association. All rights reserved. 
best for patients who present with or have a recurrence of "intracranial extension of the growth, causing visual disturbances and destruction of the clinoid processes ... for in these we know that an intracranial tumor is present." ${ }^{\prime 42}$

Whether because Dandy had described the operation just 2 years earlier or because Heuer wanted to stress the limited indications of the operation given the mortality rate of his initial series, Heuer did not spend much time describing the operation, saying that "the operation which we have employed is adequately portrayed in the accompanying illustrations drawn by $\mathrm{Mr}$. Brödel and requires little description." 42 The frontotemporal craniotomy consisted of a "very large bone flap carried well toward the supraorbital margin, with the base parallel to the zygoma." ${ }^{17,18}$ He turned an osteoplastic flap down "over the frontoparietal region on the side presenting the greatest visual or other neighborhood symptoms." 42 In addition to the large craniotomy, the procedure offered better access and visualization of the optic chiasm in an era before the modern state of illumination and magnification with the operative microscope. Heuer reported that it facilitated "cerebral dislocation," that is, retraction, allowing better access and visualization. ${ }^{42}$ Another step used to improve access included optimal head positioning. ${ }^{9,42}$ Upon dural opening (reflected concentric with the bone flap), he performed either ventricular or lumbar puncture to reduce brain "tension." 42 He then elevated the frontal lobe to bring the chiasm into view and retracted the temporal lobe posteriorly. ${ }^{9,42}$ Important features used to reduce the risk of damaging the frontal lobes included the large craniotomy, ideal head positioning, CSF egress for "cerebral dislocation" (relaxation), and the use of broad spatulas for elevation. ${ }^{42}$ He reported this as "neither a direct frontal nor a temporal (approach), but midway between the two and along the posterior margin of the anterior fossa." ${ }^{2}$ He reported it as the "shortest" (intracranial) approach to the chiasmal region. ${ }^{42}$ In the case of hypophysial lesions, he reported that upon elevation of the frontal lobes, the lesion would "immediately present itself," lifting the chiasm and coming forward over the anterior margin of the sella turcica between the optic nerves. ${ }^{42} \mathrm{He}$ stated that one of the main advantages was that the "extent of the growth and its relations to the internal carotid arteries [could] readily be determined." ${ }^{42}$ Suprasellar lesions, he believed, depressed the optic chiasm and presented behind the chiasm, yet could "be successfully attacked" if it were a cyst. ${ }^{42} \mathrm{He}$ recommended a radical approach to resection and reported attempting the removal of every lesion, regardless of size, "excepting the solid suprasellar lesions which we have found thus far impossible to remove completely." 42 Occasionally, he would complete a subtemporal decompression to aid in additional exposure and "take care of the post-operative cerebral edema." 9,42

Heuer's initial experience had a significant complication rate. ${ }^{42} \mathrm{He}$ reported sometimes being unable to sufficiently elevate the brain in some cases of large, solid suprasellar tumors. He experienced intraoperative complications of tearing the olfactory nerve from the cribriform plate, unintentional laceration of one optic nerve, tearing a tumor-infiltrated internal carotid artery at the point of entrance through the skull base requiring ligation in the neck, and two anterior cerebral artery injuries requiring ligation. ${ }^{42}$ Postoperative complications were significant as well, including convulsions, new neurological deficits, and even death from cerebral edema or hypophysial dysfunction. He documented a primary mortality rate of $37 \%$, with total mortality from additional deaths after second operations 1-3 years after the primary procedure at $46 \% .{ }^{42}$ While acknowledging the high mortality rate in his series, he also noted that his patient population was a high-risk group that had already failed a transsphenoidal operation or had been deemed ineligible for a transsphenoidal operation and historically would have been limited to a decompressive operation without tumor resection. ${ }^{42}$ The ultimate use of this operation in the setting of smaller tumors presenting earlier in the course of the disease improved outcomes, as predicted by Heuer., ${ }^{9,42}$ This technique was championed by Dandy and others and quickly became adopted by many neurosurgeons as a common approach to a number of lesions accessible through the frontotemporal corridor.

Improvements in technology and surgical techniques occurred rapidly over the ensuing decades of the 20th century. Improvements in diagnostic techniques, illumination, magnification, and neurosurgical instrumentation allowed for a more refined approach to frontotemporal lesions. ${ }^{82,89}$ With the advent of pneumoencephalography and cerebral angiography, the ability to diagnose intracranial pathology greatly improved. Further progress was made with the development of ultrasonography, CT, and MRI. These modern diagnostic modalities helped to improve our understanding of fundamental anatomical and physiological principles. The combination of preoperative planning with diagnostic modalities, neuronavigation, or even intraoperative imaging aided the neurosurgeon in developing more refined approaches than ever before. These advances led to further refinement of frontotemporal approaches, some of which will be discussed in more detail below.

\section{Operative Microscope}

Gazi Yaşargil (b. 1925) played a major role in the further refinement of frontotemporal approaches through the use of the operative microscope and the development of the pterional approach. ${ }^{53,93-96}$ Given the microscope's importance in the development of the pterional approach, its history and use in neurosurgery deserve further explanation. The first true microscope was developed around 1590 , and its invention has been attributed to two Dutch opticians, Zacharias Janssen (1585-1632) and his father, Hans Martens, who aligned two lenses within a sliding tube ${ }^{47,54}$ These were rather crude devices until Antonie van Leeuwenhoek significantly improved lens making in the late 17 th century. This improvement in lens making led to significant advances in science and medicine. ${ }^{54}$ Important progress in the realm of microscope technology did not occur again until the mid-19th century, when Ernst Abbé (1840-1905), a physicist working with Carl Zeiss (1816-1888), derived new mathematical formulas and theories that allowed the optical qualities of a lens to be predicted and standardized, allowing Zeiss to become 


\section{R. Ormond and C. G. Hadjipanayis}

the first mass producer of high-quality microscopes.$^{54} \mathrm{By}$ 1893, Zeiss introduced stereopsis with the Zeiss binocular microscope. ${ }^{54}$

While the microscope began to be used more and more in industry and research, it was not immediately accepted into surgery. Otolaryngology was the first surgical specialty to adopt true surgical microscopes, beginning with Carl Nylén (1892-1978) at the University Clinic in Stockholm in 1921 for a case of chronic otitis media. ${ }^{72}$ A colleague, Gunnar Holmgren (1875-1954), attached a light source to an existing Zeiss dissecting microscope in 1922, introducing the first binocular surgical microscope. ${ }^{25}$ These early surgical microscopes were rather crude, taking their fixation from the bony structures of the skull, and had a very limited field of vision $(6-12 \mathrm{~mm})$, lacked a freely movable support, and lacked sufficiently bright coaxial lighting. ${ }^{54,81}$ Thus, their use was limited until these problems were overcome several decades later. In the early 1950s, Hans Littmann (1908-1991) of Zeiss designed the Zeiss OPMI 1 (Zeiss Operating Microscope Number One), a surgical microscope that overcame many of these early limitations, and the microscope became widely adopted for middle ear surgery and later for ophthalmology. ${ }^{44,54,63}$

Theodore Kurze (1922-2002), at the University of Southern California, became the first neurosurgeon to use the microscope in the operating room on August 1, 1957.54 He removed a neurilemoma of the seventh cranial nerve in a 5-year-old patient, learning how to use the microscope from a year of practicing middle ear dissections in William House's (1923-2012) laboratory. ${ }^{54}$ Early support for the operating microscope in neurosurgery was similar to the endoscope's acceptance several decades later, with some even saying that it was "ridiculous" to bring it into the operating room. ${ }^{54}$ This perspective changed through several early supporters, one of whom was Gazi Yaşargil. In 1966 Hugo Krayenbühl (1902-1985), chief of neurosurgery in Zurich, Switzerland, sent Yaşargil to R. M. P. Donaghy's (1910-1991) microsurgical laboratory in Vermont. ${ }^{26,54}$ There, Yaşargil spent a year perfecting his microsurgical techniques, including the superficial temporal artery-middle cerebral artery bypass in animals, which he then successfully performed in a human on October 30, 1967. ${ }^{27}$ Together, Donaghy and Yaşargil organized the first microvascular symposium in October $1966 .^{12,13,53,54}$ Yaşargil, perhaps more than anyone, adapted the ideas of surgeons such as Kurze, Jacobson, and Donaghy and developed microsurgery into an integral part of modern neurosurgery. ${ }^{54}$ Ultimately, improved illumination and magnification allowed better precision from the surgeon and his technique, resulting in significant changes to the frontotemporal craniotomy in this same era.

\section{Pterional Craniotomy}

The pterional approach is well known to most neurosurgeons and begins with a skin incision $1 \mathrm{~cm}$ anterior and superior to the auricle extending in a direction perpendicular to the zygomatic arch and remaining behind the hairline (Fig. 3). The scalp flap is raised separately from the temporalis muscle. Yaşargil emphasized the importance of care to avoid damage to the superficially and anteriorly placed superficial temporal artery. ${ }^{94,95} \mathrm{He}$ also took great care to carefully perform interfascial dissection of the temporalis to preserve the frontotemporal branch of the facial nerve while able to "maximally retract the temporalis muscle and increase visibility along the sphenoid ridge," permitting greater exposure. ${ }^{94,95} \mathrm{He}$ described a much smaller craniotomy than Heuer, with a more cosmetically appealing skin incision, and emphasized the importance of exposure at the skull base to limit brain retraction. As far as the bony exposure was concerned, Yaşargil described the importance of removing part of the orbital roof and sphenoid wing to "greatly increase the exposed area at the base of the surgical pyramid." 95 While refined over the years, the pterional approach has been widely adopted into the armamentarium of most modern neurosurgeons as a "workhorse" approach to lesions in the frontotemporal region. ${ }^{49,67,93-96}$

\section{Keyhole Surgery}

The first neurosurgeon to use the term "keyhole surgery" was Donald H. Wilson (1927-1982) in 1971.80,91 Wilson reported on limiting exposure in cerebral surgery, stating that it "has advantages that are in keeping with the principles of good surgery." 91 Others had performed and advocated the use of small craniotomies before, but Wilson's widespread use of the approach for many indications was rather novel for the time (Fig. 4) ${ }^{80,91}$ The idea behind keyhole surgery was not simply a matter of limiting the size of the craniotomy, but was based on the principle that a small craniotomy could be rapidly opened and closed, allowing the surgeon more time to focus on the surgical target. ${ }^{91}$ Moreover, less dural opening, less brain exposure, and less retraction would decrease morbidity and improve wound healing. ${ }^{77,78,80,91}$ Important in any small craniotomy is the appropriateness of the approach to the lesion. Careful study of preoperative images coupled with the use of neuronavigation or intraoperative imaging modalities, such as ultrasonography, angiography, CT, or MRI, can help to select the most appropriate anatomical corridor. Intraoperative adjuncts, such as the microscope or endoscope, also prove very useful for keyhole surgery. ${ }^{74,77,78,80,91}$

Wilson's keyhole approach involved the use of $8-\mathrm{cm}$ incisions and a 2-in trephine, except in the temporal region where a craniectomy was performed. ${ }^{91}$ He used a D'Errico trephine with a 2-in diameter fitted to a Hall Neurairtome using a Hudson drill adapter to perform the craniotomy. ${ }^{91}$ This required some expertise, as a removable twist drill was inserted into the center of the trephine to catch the bone and anchor the trephine. The trephine was then used to make a shallow groove before removing the twist drill. Then the trephine was used to complete the craniotomy, removing the disc of bone with a periosteal elevator. ${ }^{11}$ At the end of the procedure, Wilson used stainless steel wire to replace the bone. ${ }^{91}$ While describing this approach in 139 cases, Wilson himself stated he made "no fetish of keyhole surgery" and used larger craniotomies as appropriate, depending on the presenting pathology in a given patient. ${ }^{91}$

Additional keyhole surgeries have been described 


\section{Development of the frontotemporal craniotomy}
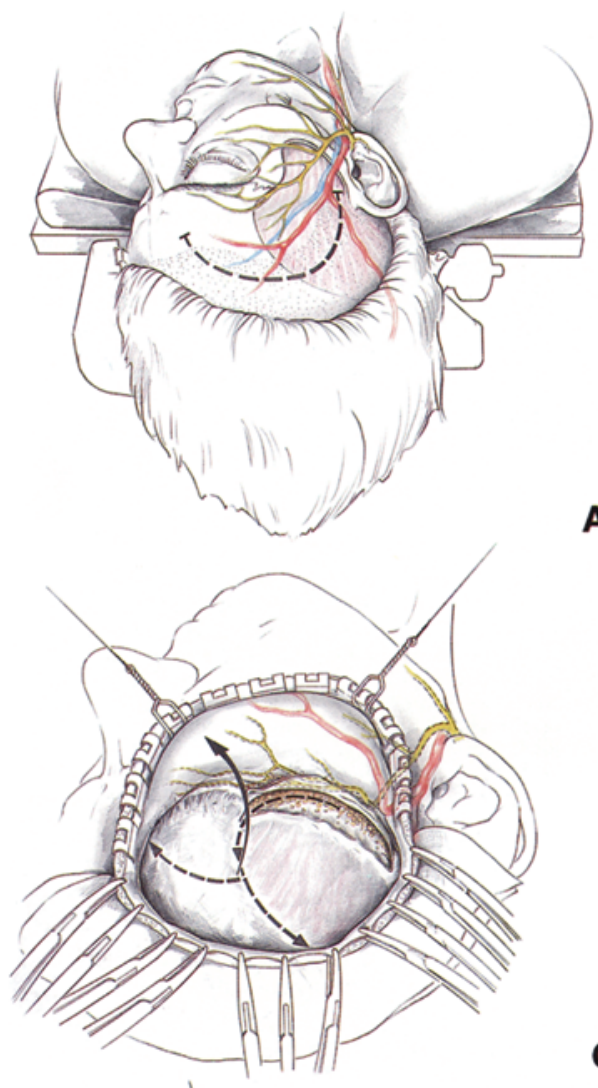

A

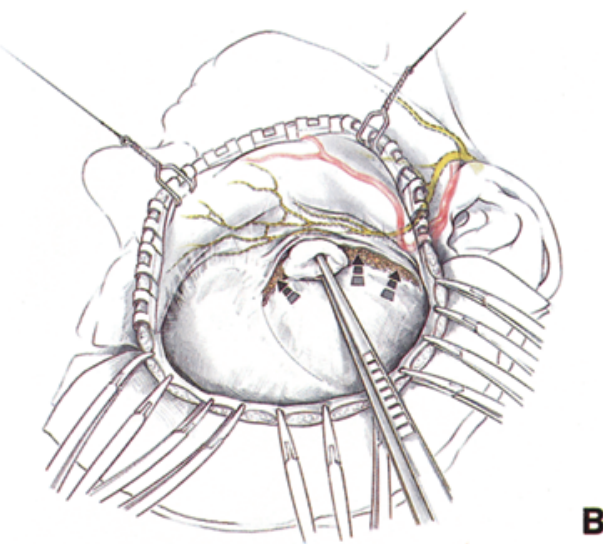

B

C
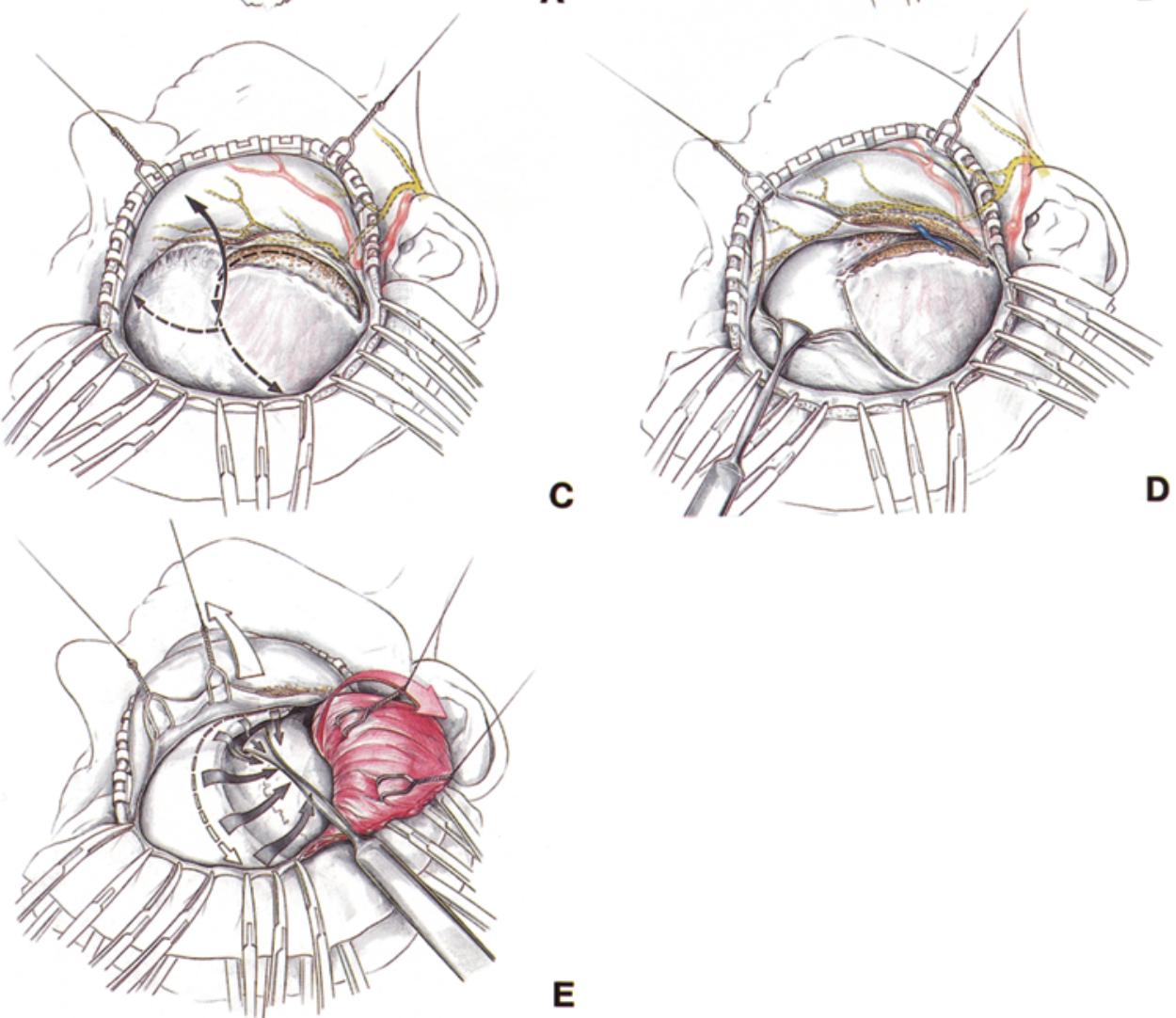

FIG. 3. Drawings of the pterional craniotomy after Yaşargil. Reprinted with permission from Yaşargil et al: J Neurosurg 67:463466, 1987.

more recently, especially for a subfrontal approach to the frontotemporal region, although a keyhole pterional approach has also been described for lateral approaches. ${ }^{67,74}$ Many authors have advocated a small frontal craniotomy through an eyebrow incision, as first popularized by Axel Perneczky (1945-2009). ${ }^{77}$ Head and bed positioning are important in these approaches, as are the use of either microscopic or endoscopic assistance for appropriate illumination and visualization at depth. ${ }^{74,80}$ In this approach, it is important to place the skin incision lateral to the supraorbital notch to avoid numbness, and to carefully dissect laterally to avoid damage to the frontalis branch of the facial nerve. ${ }^{74,77,78,80}$ A large frontal sinus may preclude the use of this approach in a given patient, because it is important to have a craniotomy at least $1.5-2 \mathrm{~cm}$ in width to allow manipulation of microsurgical instruments. ${ }^{74}$ Over 2500 cases using this approach have been reported in the literature. ${ }^{74}$ Perneczky reported that it was an improved approach to the suprasellar location because the "suprasellar anatomic structures are free for surgical dissection and are not hidden by any brain structures." ${ }^{80}$ His claims that the "optical field widened with increasing distance from the keyhole, and that contralateral structures could be visualized well" were also recently studied in a cadaveric cohort. ${ }^{15}$ The authors compared the keyhole supraorbital approach to the pterional and larger supraorbital craniotomies and noted that the difference in the area of exposure between approaches was less than $1 \mathrm{~cm}$ for ipsilateral or contralateral lesions in the parasellar region. ${ }^{15}$ The limitations of this approach seem to be more 

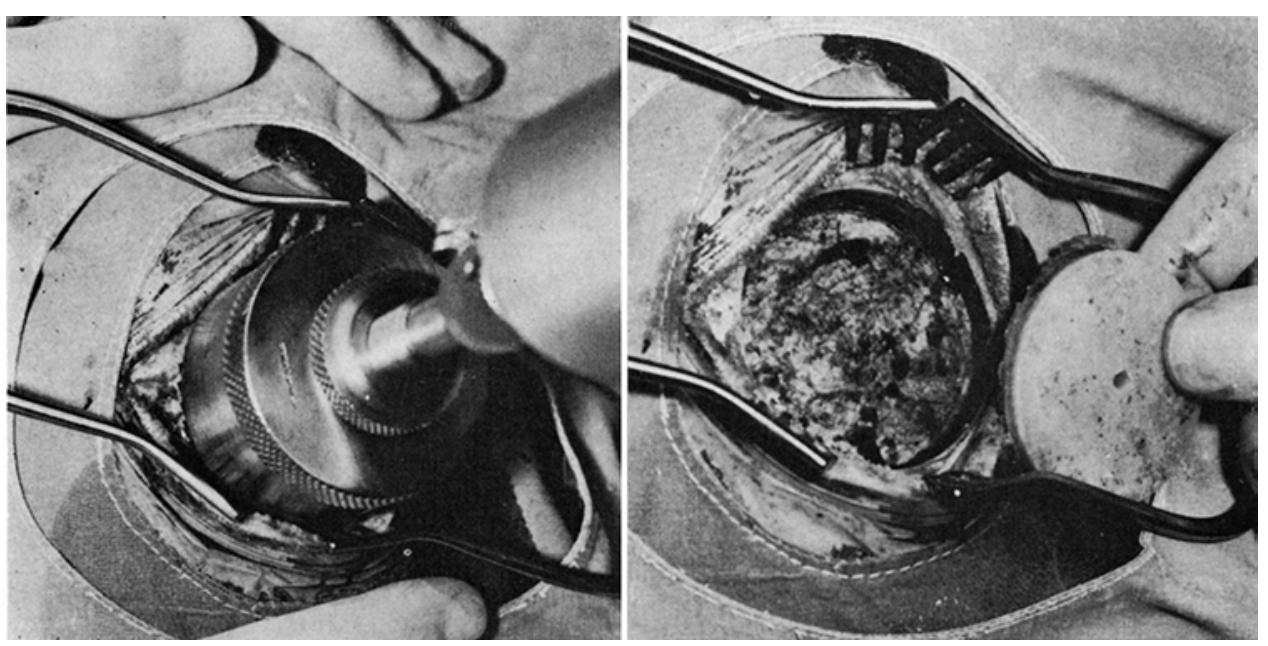

Fig. 4. Wilson's keyhole craniotomy. Reprinted with permission from Wilson: J Neurosurg 34:102-106, 1971.

related to the "surgical freedom" of microinstruments or cosmetic concerns with poor technique. ${ }^{15,74,80}$ Moreover, in the setting of vascular pathologies, prematurely ruptured aneurysms may be difficult to manage using this approach, and some have recommended against this approach for these reasons. ${ }^{15,41,68,97}$

\section{Endoscopic Approaches}

Just as the microscope revolutionized neurosurgery a generation ago, endoscopic technology has advanced in more recent history to be a common adjunct in many neurosurgical procedures. Endoscopy was first used in neurosurgery more than a century ago. In 1910, Victor Lespinasse (1878-1946), a Chicago urologist, performed the first neuroendoscopic procedure on a neonate with hydrocephalus (fulgurating the choroid plexus). ${ }^{19}$ Then, in 1922, Walter Dandy published the first endoscopic view of the ventricular system, coining the term "ventriculoscopy," followed by the successful removal of the choroid plexus 1 year later.,17,21,40 It was that same year (1923) that William J. Mixter (1880-1958), a neurosurgeon at Massachusetts General Hospital, performed the first successful endoscopic third ventriculostomy in a child with congenital obstructive hydrocephalus..$^{40,69}$ Despite these early attempts, endoscopy long remained in the background, as endoscopic technology took several decades to advance and to become more relevant in neurosurgery. ${ }^{1,21}$ Interest in neuroendoscopy has always been closely related to technical improvements. One of the major advances came in the early 1960s, when Fourestier and Vulmiére placed the light source outside the device where its intensity could be regulated. ${ }^{21}$ This was possible by using a light silica guide to drive the light into the endoscope. This increased illumination dramatically and led Gerard Guiot (1912-1998) to use this endoscope for the first time in neurosurgery at the Foch Hospital in Paris on August 8, $1962 .{ }^{21}$ This gradually increased interest in neuroendoscopy, with innovative surgeons and inventors improving the technology of and surgical indications for the endoscope over time.

Historically, one of the main disadvantages of the more refined neurosurgical approaches was poor visualization due to inadequate illumination. Thus, small craniotomies are as much a product of technological development as surgical innovation. Keyhole surgery itself requires frequent changing of the visual angle of the microscope to allow illumination in the area of interest deep in the surgical field. Endoscopes mitigate the need for this by providing illumination at depth without casting shadows, and when held by a retractor arm or assistant, endoscopes allow the surgeon to continue a bimanual surgical technique. ${ }^{74}$ Angled lenses allow visualization around corners without retraction and can help to improve the extent of tumor resection despite smaller craniotomies. ${ }^{88,97}$ Endoscopes provide a surgical view that is different from that provided by microscopes. Multiple studies have demonstrated the benefits of their use as an adjunct to or a replacement for the operative microscope, depending on the procedure. . $3,23,24,46$ Recent studies have developed an ever-expanding list of pathologies accessible endoscopically, especially through the endonasal corridor. ${ }^{37,56,65}$ As these approaches mature, endoscopy will become a more commonly used technology to aid the neurosurgeon in the operating room, just as the microscope did a generation ago.

\section{Conclusions}

The history of the craniotomy is filled with descriptions of brave surgeons performing surgery against great odds in an attempt to improve outcomes in their patients. In the distant past, it was more common to not operate on brain pathology because of the high risk of mortality from hemorrhage and postoperative infection. The lack of advancement beyond trephination for very basic indications lasted for centuries in the Latin West. Finally, scientific advances in antisepsis, anesthesia, hemostasis, and cerebral localization allowed rapid and significant advances in neurosurgery. Brilliant illumination and magnification via the operative microscope and endoscope also permitted advancement of the craniotomy for various neurosurgical problems. This also holds true in the history of the development of approaches to the frontotemporal region. 
Over time, approaches and outcomes have improved, providing neurosurgical patients with dramatically better outcomes than those in past centuries. With continuing research and further scientific advances, the future is bright, and "the tendency will always be in the direction of exercising greater care and refinement in operating." 38

\section{Disclosure}

The authors report no conflict of interest concerning the materials or methods used in this study or the findings specified in this paper.

Author contributions to the study and manuscript preparation include the following. Conception and design: Ormond. Acquisition of data: Ormond. Analysis and interpretation of data: Ormond. Drafting the article: both authors. Critically revising the article: both authors. Reviewed submitted version of manuscript: both authors. Approved the final version of the manuscript on behalf of both authors: Ormond. Administrative/technical/material support: Ormond. Study supervision: Ormond.

\section{References}

1. Abbott R: History of neuroendoscopy. Neurosurg Clin N Am 15:1-7, 2004

2. Ahn Y: Transforaminal percutaneous endoscopic lumbar discectomy: technical tips to prevent complications. Expert Rev Med Devices 9:361-366, 2012

3. Ammirati M, Wei L, Ciric I: Short-term outcome of endoscopic versus microscopic pituitary adenoma surgery: a systematic review and meta-analysis. J Neurol Neurosurg Psychiatry 84:843-849, 2013

4. Bennett AH, Godlee RJ: Case of cerebral tumor. Med Chir Trans 68:243-275, 1885

5. Berengario da Carpi J: Commentaria cum Amplissimis Additionibus Super Anatomia Mundini. Bologna, Italy: Hieronymus de Benedictus, 1521

6. Berengario da Carpi J: De Fractura Cranii Liber Aureus. Bologna, Italy: Lugdunum Batavorum, 1651

7. Berengario da Carpi J: Isagogae Breues et Exactissimae in Anatomia Humani Corporis. Bologna, Italy: Henricus Sybold, 1529

8. Berengario da Carpi J: Tractatus de Fractura Calve Sive Cranei. Bologna, Italy: Hieronymus de Benedictus, 1518

9. Borden WB, Tamargo RJ: George J. Heuer: forgotten pioneer neurosurgeon at the Johns Hopkins Hospital. J Neurosurg 96:1139-1146, 2002

10. Broca P: Perte de la parole; ramollissement chronique et destruction partielle dulobe antérieur gauche du cerveau. Bull Soc Anthropol 2:235-243, 1861

11. Broca P: Remarques sur le siége de la faculté du langage articulé suivie d'une observation d'aphémie (perte de la parole). Bull Soc Anat Paris 6:330-337, 1861

12. Buncke HJ: Forty years of microsurgery: what's next? J Hand Surg Am 20:S34-S45, 1995

13. Buncke HJ: Microsurgery-retrospective. Clin Plast Surg 13: 315-318, 1986

14. Caton R: Notes of a case of acromegaly treated by operation. Br Med J 2:1421-1423, 1893

15. Cheng CM, Noguchi A, Dogan A, Anderson GJ, Hsu FP, McMenomey SO, et al: Quantitative verification of the keyhole concept: a comparison of area of exposure in the parasellar region via supraorbital keyhole, frontotemporal pterional, and supraorbital approaches. Laboratory investigation. J Neurosurg 118:264-269, 2013

16. Clark FC: A brief history of antiseptic surgery. Med Library Hist J 5:145-172, 1907
17. Dandy WE: Cerebral ventriculoscopy. Bull Johns Hopkins Hosp 33:189-190, 1922

18. Dandy WE: A new hypophysis operation. Bull Johns Hopkins Hosp 29:154-155, 1918

19. Davis L: Neurological Surgery. Philadelphia: Lea \& Febiger, 1936

20. Davy H: Researches, Chemical and Philosophical-Chiefly Concerning Nitrous Oxide or Dephlogisticated Nitrous Air, and its Respiration. London: J Johnson, 1800

21. Decq P, Schroeder HWS, Fritsch M, Cappabianca P: A history of ventricular neuroendoscopy. World Neurosurg 79 (2 Suppl):S14.e1-S14.e6, 2013

22. Desai SP, Desai MS, Pandav CS: The discovery of modern anaesthesia-contributions of Davy, Clark, Long, Wells and Morton. Indian J Anaesth 51:472-478, 2007

23. Di X, Sui A, Hakim R, Wang M, Warnke JP: Endoscopic minimally invasive neurosurgery: emerging techniques and expanding role through an extensive review of the literature and our own experience - part I: intraendoscopic neurosurgery. Pediatr Neurosurg 47:315-326, 2011

24. Di X, Sui A, Hakim R, Wang M, Warnke JP: Endoscopic minimally invasive neurosurgery: emerging techniques and expanding role through an extensive review of the literature and our own experience - part II: extraendoscopic neurosurgery. Pediatr Neurosurg 47:327-336, 2011

25. Dohlman GF: Carl Olof Nylén and the birth of the otomicroscope and microsurgery. Arch Otolaryngol 90:813-817, 1969

26. Donaghy RM: The history of microsurgery in neurosurgery. Clin Neurosurg 26:619-625, 1979

27. Donaghy RM: Neurosurgeon of the year: Mahmut Gazi Yasargil. Surg Neurol 13:1-3, 1980

28. Egerton FN: A history of the ecological sciences, part 19: Leeuwenhoek's microscopic natural history. Bull Ecol Soc Am 87:47, 2006

29. Feinstein S: Louis Pasteur: The Father of Microbiology. Berkeley Heights, NJ: Enslow, 2008

30. Ferrier D: The Functions of the Brain. London: Smith, Elder, \& Co, 1876

31. Flourens P: [Experimental Research on the Properties and Functions of the Nervous System in Vertebrate Animals.] Paris: Crevot, 1824 (Fr)

32. Flourens P: Phrenology Examined. Philadelphia: Hogan \& Thompson, 1846

33. Fritsch GT, Hitzig E: Über die elektrische Erregbarkeit des Grosshirns. Arch Anat Physiol Wiss Med 37:300-332, 1870

34. Gall FJ: On the Functions of the Brain and Each of Its Parts. Boston: Marsh, Capen \& Lyon, 1835

35. Goodrich JT, Flamm ES: Historical overview of neurosurgery, in Winn HR (ed): Youmans Neurological Surgery, ed 6. Philadelphia: Elsevier, 2011, Vol 1, pp 3-38

36. Gowers WR, Horsley V: A case of tumour of the spinal cord. Removal, recovery. Med Chir Trans 71:377-430.11, 1888

37. Graffeo CS, Dietrich AR, Grobelny B, Zhang M, Goldberg $\mathrm{JD}$, Golfinos JG, et al: A panoramic view of the skull base: systematic review of open and endoscopic endonasal approaches to four tumors. Pituitary [epub ahead of print], 2013

38. Halsted WS: Surgical Papers. Baltimore: Johns Hopkins Press, 1924, Vol 1, p 36

39. Harvey W: De Motu Cordis. Frankfurt: Guilielmi Fitzeri, 1628

40. Hellwig D, Grotenhuis JA, Tirakotai W, Riegel T, Schulte DM, Bauer BL, et al: Endoscopic third ventriculostomy for obstructive hydrocephalus. Neurosurg Rev 28:1-38, 2005

41. Heros RC: Editorial. The supraorbital "keyhole" approach. J Neurosurg 114:850-851, 2011

42. Heuer GJ: Surgical experiences with an intracranial approach to chiasmal lesions. Arch Surg 1:368-381, 1920

43. Hippocrates: De capitus vulneribus, in: The Genuine Works 


\section{R. Ormond and C. G. Hadjipanayis}

of Hippocrates. Adams F (trans). London: Sydenham Society, 1849 , pp 421-466

44. Hoerenz P: Magnification: loupes and the operating microscope. Clin Obstet Gynecol 23:1151-1162, 1980

45. Horsley V: On the technique of operations on the central nervous system. Br Med J 2:411-423, 1906

46. Ivan ME, Jahangiri A, El-Sayed IH, Aghi MK: Minimally invasive approaches to the anterior skull base. Neurosurg Clin N Am 24:19-37, 2013

47. Kalderon AE: The evolution of microscope design from its invention to the present days. Am J Surg Pathol 7:95-102, 1983

48. Kiliani OGT: II. Some remarks on tumors of the chiasm, with a proposal how to reach the same by operation. Ann Surg 40:35-43, 1904

49. Kim E, Delashaw JB Jr: Osteoplastic pterional craniotomy revisited. Neurosurgery 68 (1 Suppl Operative):125-129, 2011

50. Kramer SN: First pharmacopeia in man's recorded history. Am J Pharm Sci Support Public Health 126:76-84, 1954

51. Krause F: Bemerkungen zur Operation der Hypophysen-geschwülste. Dtsch Med Wochenschr 53:691-694, 1927

52. Krause F: Schussverletzungen des Schädels, in von Leyden E, Klemperer F (eds): Die Deutsche Klinik am Eingange des Zwanzigsten Jahrhunderts in Akademischen Vorlesungen. Berlin: Urban \& Schwarzenberg, 1905, pp 1002-1004

53. Krayenbühl H, Yaşargil MG: [The use of binocular microscopes in neurosurgery.] Wien Z Nervenheilkd Grenzgeb 25: 268-277, 1967 (Ger)

54. Kriss TC, Kriss VM: History of the operating microscope: from magnifying glass to microneurosurgery. Neurosurgery 42:899-908, 1998

55. Landolt AM: History of pituitary surgery, in Greenblatt $\mathrm{SH}$, Dagi TF, Epstein MH (eds): A History of Neurosurgery: In Its Scientific and Professional Contexts. Park Ridge, IL: American Association of Neurological Surgeons, 1997, pp 373-400

56. Lee DL, McCoul ED, Anand VK, Schwartz TH: Endoscopic endonasal access to the jugular foramen: defining the surgical approach. J Neurol Surg B Skull Base 73:342-351, 2012

57. Lerner KL, Lerner BW (eds): World of Microbiology and Immunology. Detroit: Gale, 2007

58. Lister J: On a new method of treating compound fracture, abscess, etc., with observation on the conditions of suppuration. Lancet 89:326-329, 1867

59. Lister J: On the antiseptic principle in the practice of surgery. Br Med J 2:246-248, 1867

60. Long CW: An account of the first use of sulfuric ether by inhalation as an anaesthetic in surgical operations. South Med Surg J 5:705-713, 1849

61. Lower R: Tractatus de corde. Amsterdam: Apud Danielem Elzevirium, 1669

62. Lyman HM: History of anaesthesia, in: Artificial Anaesthesia and Anaesthetics. New York: William Wood \& Co, 1881, pp 1-7

63. Malis LI: Instrumentation and techniques in microsurgery. Clin Neurosurg 26:626-636, 1979

64. Manzoni T: The cerebral ventricles, the animal spirits and the dawn of brain localization of function. Arch Ital Biol 136: 103-152, 1998

65. Mason E, Van Rompaey J, Carrau R, Panizza B, Solares CA: Anatomical and computed tomographic analysis of the transcochlear and endoscopic transclival approaches to the petroclival region. Laryngoscope 124:628-636, 2014

66. Massarweh NN, Cosgriff N, Slakey DP: Electrosurgery: history, principles, and current and future uses. J Am Coll Surg 202:520-530, 2006

67. McLaughlin N, Cutler A, Martin NA: Technical nuances of temporal muscle dissection and reconstruction for the pterional keyhole craniotomy. Technical note. J Neurosurg 118: 309-314, 2013

68. Mitchell P, Vindlacheruvu RR, Mahmood K, Ashpole RD,
Grivas A, Mendelow AD: Supraorbital eyebrow minicraniotomy for anterior circulation aneurysms. Surg Neurol 63: 47-51, 2005

69. Mixter WJ: Ventriculoscopy and puncture of the floor of the third ventricle. Boston Med Surg J 188:277-278, 1923

70. Morton WTG: Remarks on the Proper Mode of Administering Sulfuric Ether by Inhalation. Boston: Button \& Wentworth, 1847

71. Nogueira de Almeida A, Alho EJ, Teixeira MJ: Models of functional cerebral localization at the dawning of modern neurosurgery. World Neurosurgery [epub ahead of print], 2013

72. Nylén CO: The otomicroscope and microsurgery 1921-1971. Acta Otolaryngol 73:453-454, 1972

73. Ogston WH, Cowan HH, Smith H: Alexander Ogston: Memories and Tributes of Relatives, Colleagues and Students, With Some Autobiographical Writings. Aberdeen, Scotland: Aberdeen University Press, 1943

74. Ormond DR, Hadjipanayis CG: The supraorbital keyhole craniotomy through an eyebrow incision: its origins and evolution. Minim Invasive Surg 2013:296469, 2013

75. Paré A: Dix Livres de la Chirurgie Avec le Magasin des Instruements Necessaries à Icelle. Paris: Jean Le Royer, 1564

76. Park K: The criminal and the saintly body: autopsy and dissection in Renaissance Italy. Renaiss Q 47:1-33, 1994

77. Perneczky A: Planning strategies for the suprasellar region. Philosophy of approaches. Neurosurgeons 11:343-348, 1992

78. Perneczky A, Müller-Forell W, van Lindert E, Fries G: Keyhole Concept in Neurosurgery. Stuttgart: Thieme Medical Publishers, 1999

79. Powell MA: Wine and the vine in ancient Mesopotamia: the cuneiform evidence, in McGovern PE, Fleming SJ, Katz SH (eds): The Origins and Ancient History of Wine. Food and Nutrition in History and Anthropology, Vol 11. Amsterdam: Gordon and Breach, 1996, pp 96-124

80. Reisch R, Perneczky A: Ten-year experience with the supraorbital subfrontal approach through an eyebrow skin incision. Neurosurgery 57 (4 Suppl):242-255, 2005

81. Rice JC: The microsurgical revolution in otolaryngology. Med J Aust 2:1011-1014, 1972

82. Roger of Salerno: Practica chirurgiae, in Guy de Chauliac (ed): Cyrurgia et Cyrurgia Bruni, Teodorici, Rolandi, Lanfranci, Rogerii, Bertapalie. Venice: Bernardinus Venetus de Vitalibus, 1519

83. Roper-Hall MJ: Microsurgery in ophthalmology. Br J Ophthalmol 51:408-414, 1967

84. Semmelweis I: Semmelweis's Gesammelte Werke. Herausgegeben und zum Theil aus dem Ungarischen Übersetzt on Dr. Tiberius Von Gyory. Jena: Gustav Fischer, 1905, p 604

85. Simpson JY: Account of a New Anaesthetic Agent, as a Substitute for Sulphuric Ether in Surgery and Midwifery. Edinburgh: Sutherland \& Knox, 1847

86. Sturgis CC: The history of blood transfusion. Bull Med Libr Assoc 30:105-112, 1942

87. Thorwald J: Im zerbrechlichen Haus der Seele. Die große Odyssee der Gehirnchirurgie. Munich: Droemer-Knaur Verlag, 1986

88. van Lindert E, Perneczky A, Fries G, Pierangeli E: The supraorbital keyhole approach to supratentorial aneurysms: concept and technique. Surg Neurol 49:481-490, 1998

89. Wernicke C: Der aphasische Symptomenkomplex. Breslau: M Cohn \& Weigert, 1874

90. Wilkins RH: Neurosurgical classics-IV. J Neurosurg 19: 1098-1103, 1962

91. Wilson DH: Limited exposure in cerebral surgery. Technical note. J Neurosurg 34:102-106, 1971

92. Wyklicky H, Skopec M: Ignaz Philipp Semmelweis, the prophet of bacteriology. Infect Control 4:367-370, 1983

93. Yaşargil MG: Microneurosurgery. Microsurgical Anatomy of the Basal Cisterns and Vessels of the Brain, Diagnostic 


\section{Development of the frontotemporal craniotomy}

Studies, General Operative Techniques and Pathological Considerations of the Intracranial Aneurysms. Stuttgart: Georg Thieme Verlag, 1984, Vol 1, pp 217-220

94. Yaşargil MG, Antic J, Laciga R, Jain KK, Hodosh RM, Smith RD: Microsurgical pterional approach to aneurysms of the basilar bifurcation. Surg Neurol 6:83-91, 1976

95. Yaşargil MG, Reichman MV, Kubik S: Preservation of the frontotemporal branch of the facial nerve using the interfascial temporalis flap for pterional craniotomy. Technical article. J Neurosurg 67:463-466, 1987

96. Yaşargil MG, Teddy PJ, Roth P: Selective amygdalo-hippocampectomy. I: Operative anatomy and surgical technique, in Symon L (ed): Advances and Technical Standards in Neurosurgery, Vol 12. Wien: Springer-Verlag, 1985, pp 93-123
97. Zheng X, Liu W, Yang X, Gong J, Shen F, Shen G, et al: Endoscope-assisted supraorbital keyhole approach for the resection of benign tumors of the sellar region. Minim Invasive Ther Allied Technol 16:363-366, 2007

Manuscript submitted December 3, 2013.

Accepted February 18, 2014.

Please include this information when citing this paper: DOI: 10.3171/2014.2.FOCUS13548

Address correspondence to: D. Ryan Ormond, M.D., Department of Neurosurgery, University of Bonn, Sigmund-Freud-Strasse 25, Bonn 53105, Germany. email: drormond@uni-bonn.de. 